\title{
Predicting Risk of Chronic Hypertension in Women with Preeclampsia Based on Placenta Histology. A Prospective Cohort Study in Cuba.
}

Simon Byonanuwe ( $\boldsymbol{D}$ byonsimon@gmail.com )

Kampala International University - Western Campus https://orcid.org/0000-0001-7953-5814

\section{Yarine Fajardo}

Granma University of Medical sciences and Kampala International University Western Campus

\section{Danilo Nápoles}

Santiago de Cuba University of Medical Sciences

\section{Alexis Alvarez}

Granma University of Medical Sciences, Cuba

\section{Yaimi Cèspedes}

Granma University of Medical Sciences

\section{Robinson Ssebuufu}

Kampala International University-Western Campus

\section{Research article}

Keywords: Chronic hypertension, Placental histology, Preeclampsia, Postpartum.

Posted Date: August 20th, 2020

DOI: https://doi.org/10.21203/rs.3.rs-44764/v1

License: () (1) This work is licensed under a Creative Commons Attribution 4.0 International License. Read Full License 


\section{Abstract}

Background: Chronic hypertension is one of the major sequelae of preeclampsia with associated long term morbidity and mortality among previously normotensive women diagnosed with preeclampsia. We identified the predictors of developing this complication in women with preeclampsia admitted at the Carlos Manuel de Cèspedes Teaching Hospital in Cuba based on histological assessment of their placenta so as to guide the health care providers in early identification of the patients at risk for timely intervention against this vicious condition.

Methods: A three-year prospective cohort study was conducted between March 2017 and March 2020. A cohort of 178 women diagnosed with preeclampsia was recruited and followed up at 12 weeks postpartum for chronic hypertension. Histological studies were done on their placenta following delivery and the respective result forms used to collect the data. Cox's hazards regression model was applied to estimate the risk using STATA version 14.2.

Results: Chorioamnionitis (HR=1.697, 95\% Cl: 1.443-3.416, $p=0.038)$, villositary infarcts ( $\mathrm{HR}=1.657,95 \% \mathrm{Cl}$ : 1.264-2.848, $p=0.048)$, intervillositary thrombus ( $\mathrm{HR}=1.529,95 \% \mathrm{Cl}: 1.231-3.197, p=0.020)$, and endarteritis (HR=1.242, 95\%Cl: 1.115-1.804, $p=0.025)$ placental lesions were predictive of chronic hypertension at 12 weeks postpartum.

Conclusion: Placental histology in women with preeclampsia is key towards improving the ability to diagnose and monitor those likely to develop chronic hypertension before its onset for timely intervention.

\section{Background}

Chronic hypertension and preeclampsia remain one of the most intriguing hypertensive disease conditions among obstetricians all over the world with associated high maternal and neonatal morbidity and mortality (1). The two are part of the four classification criteria for the different forms of hypertensive disorders of pregnancy; the other two being gestational hypertension and preeclampsia superimposed on chronic hypertension (2)(3)(4). Chronic hypertension is defined as one (systolic blood pressure more than or equal to $140 \mathrm{mmHg}$ and diastolic blood pressure more than or equal to $90 \mathrm{mmHg}$ taken four to six hours apart) that is diagnosed before pregnancy or before 20 weeks of gestation; or one that is first diagnosed after 20 weeks' gestation and persists for greater than 12 weeks postpartum (5)(6)(7). In Cuba, preeclampsia is among the leading causes of maternal deaths and there has been an apparent rise in the proportion of maternal mortality related to hypertensive disorders of pregnancy since 2009 even though numbers are small (for example, a rate of 3.2 per 100,000 live births was reported in 2012) (8). Generally, a high future risk of up to $14.8 \%$ of developing chronic hypertension in women with preeclampsia (versus $5.6 \%$ in those without preeclampsia) has been reported (9). This persistent (chronic) hypertension has been noted to be a major threat to the quality of life of the women (10) with greatly increased risk of adverse cardiovascular events such as stroke, renal failure and coronary heart diseases $(11)(12)(7)(13)$ (14)(15). 
The predictive factors for chronic hypertension following preeclampsia pregnancies however remain not very clear; not only in Cuba but even to most of the other parts of the world. For quite a long time, the placenta has attracted a lot of attention among many scholars world over with regard to its role in the aetiopathology of preeclampsia. Most theories relate to a failed transformation of the spiral arteries during placentation with subsequent release of certain factors which lead to endothelial dysfunction, generalized vasospasms and ultimately impaired multiple organ function (16)(17)(18)(19). The altered organ function can lead to persistence of hypertension depending on the severity of the endothelial dysfunction even after delivery of the placenta (13). Early interventions tailored at controlling the high blood pressure during the postpartum period may result in reduction in associated morbidity and mortality resulting from this chronic hypertension (20)(21). The aim of the current study was to identify the histological predictors of this persistent hypertension based on the patient's placenta following delivery so as to guide in easy and timely identification of those at risk for early initiation of relevant interventions so as to minimize associated complications.

\section{Methods}

This was a prospective cohort study conducted collaboratively between Granma University of Medical Sciences in Cuba and Kampala International University in Uganda over a period of three years in the months of March 2017 to March 2020. The study was conducted in the hypertension unit of Obstetrics and Gynaecology department of Carlos Manuel de Cèspedes Teaching Hospital located in Bayamo city, Granma Province, Southeastern Cuba. This is a public tertiary teaching hospital for the University of Medical Science of Granma with a bed capacity of 879 . The obstetric unit where the study was done has a bed capacity of 234 and conducts about 5000 deliveries per year according to the hospital records of 2019. A total of 178 pregnant women above 24 weeks of gestation admitted in the hypertension unit with a diagnosis of preeclampsia that consented to participate in the study were enrolled. Consecutive enrolment of all the pregnant women who met the inclusion criteria for the study was done until the required sample size was realised. Diagnosis of preeclampsia was made following the American College of Obstetricians and Gynaecologists' protocol 2016 (12). Preeclampsia was defined as the presence of hypertension of $140 / 90 \mathrm{mmHg}$ or more repeated four hours apart with proteinuria of +1 or more in a previously normotensive patient above 20 weeks of gestation (22)(23). Only women above 24 weeks of gestation were however included in the study since we also targeted doppler ultrasound scan results at 24 weeks of gestation. Women with preeclampsia superimposed on chronic hypertension were excluded from the study since they were already chronically hypertensive. Women with known history of kidney disease were also excluded from the study since serum creatinine was one of our study variables. This is usually deranged in patients with kidney disease. These three variables were particularly being considered in a different investigation. Sample size was 178, estimated using Daniel's formula (24).

Voluntary recruitment of all the study participants was done. Informed written consent from the participants was obtained after fully explaining the details of the study in Spanish, the national language for Cuba. An informed consent document in Spanish language approved by the research ethics committee of Carlos Manuel de Cèspedes Teaching Hospital was signed by every participant, the 
investigator and a witness. Participants were not forced to enroll if they did not want to. The participant was free to withdraw from the study at any time she wished, without coercion or compromise of care that she was entitled to. Blood pressure measurements were done using a manual mercury sphygmomanometer using the right hand at the level of the heart with the patient in sitting position. All the enrolled participants were managed according to the hospital protocol which includes antihypertensive drugs, administration of magnesium sulfate for those with severe preeclampsia and subsequently delivery. A histopathologist was notified of any impending delivery. On delivery, the placenta was received on a bowl and then assessed for any gross abnormalities. Samples were then collected in $10 \%$ formaldehyde solution and transported to the histopathology laboratory within ten minutes for further analysis. Here, the tissues were stained using Haematoxylin and Eosin (H\&E) and analyzed for any abnormalities such as intervillository thrombus, villository infarcts, tennar parker changes, placental hypermaturity, chorioamnionitis, meconium, decidual necrosis and endarteritis. $10 \%$ of our samples were sent to an independent histopathologic laboratory in Bayamo province for analysis for purposes of quality assurance. To avoid bias, every 10 th sample was submitted for this cause. Laboratory forms were used to collect the data. Participants were followed up at twelve weeks post-delivery and their blood pressure measurements re-taken as already explained above so as to ascertain their blood pressure status. Those whose blood pressure were still above or equal to $140 \mathrm{mmHg}$ systolic and $90 \mathrm{mmHg}$ diastolic were considered to have chronic hypertension. Individuals with a systolic blood pressure lower than $140 \mathrm{mmHg}$ and diastolic blood pressure lower than $90 \mathrm{mmHg}$ were defined as normotensive. All the collected data were entered into Microsoft excel version 2010 and then imported into STATA version 14.2 for analysis. Both univariate and Cox's multivariate model analyses were carried out to estimate the risk. The variables in the final multivariate model were significant when $p<0.05$. The measure of association was reported as hazard ratios with corresponding $95 \%$ confidence interval and $p$-value.

\section{Results}

A total of 178 women with preeclampsia were enrolled over the period of three years. Nine patients were however excluded from the study due to superimposed preeclampsia on chronic hypertension. Four women had history of isolated renal disease (that is, had history of only renal disease without chronic hypertension) and were also excluded while three patients failed to attend the postnatal follow-up at twelve weeks. Therefore, only 162 patients were successfully studied and data analyzed. Out of a cohort of 162 participants, $45(27.8 \%)$ had chronic hypertension at twelve weeks postpartum. The most common pathological findings were endarteritis $93(57.4 \%)$, followed by villository infarcts $42(25.9 \%)$ and chorioamnionitis $25(15.4 \%)$. We noted very few cases of decidual artery disease $3(1.9 \%)$ and this was the lowest histopathological finding found. These are shown in Table 1.

We run a univariate analysis model for risk of chronic hypertension in this cohort of women with preeclampsia based on the placenta histopathological findings which revealed four variables statistically significant; that is, intervillositary thrombus, villositary infarcts, endarteritis, and chorioamnionitis ( $p<$ 0.001).This is shown in Table 2. Cox's multivariate model analysis showed that placental lesions, that is; chorioamnionitis $(\mathrm{HR}=1.697,95 \% \mathrm{Cl}: 1.443-3.416, p=0.038)$, villositary infarcts $(\mathrm{HR}=1.657,95 \% \mathrm{Cl}$ : 
$1.264-2.848, p=0.048)$, intervillositary thrombus ( $\mathrm{HR}=1.529,95 \% \mathrm{Cl}: 1.231-3.197, p=0.020)$, and endarteritis $(H R=1.242,95 \% \mathrm{Cl}: 1.115-1.804, p=0.025)$ were independently associated with high risk for developing chronic hypertension at twelve weeks postpartum. This is shown in Table 3.

Table 1

Characterization of the samples for Predictors of Risk of Chronic Hypertension in Women with Preeclampsia based on Placenta Histology at Manuel de Cèspedes Teaching Hospital $(\mathrm{N}=162)$

\begin{tabular}{|llll|}
\hline Variable & Category & Frequency & Percent (\%) \\
\hline Decidual artery diseases & Yes & 3 & 1.9 \\
\hline Tenney parker changes & No & 159 & 98.1 \\
\hline & Yes & 21 & 13 \\
\hline Placental hypermaturity & No & 141 & 87 \\
\hline & Yes & 6 & 3.7 \\
\hline Intervillositary thrombus & No & 156 & 96.3 \\
\hline & Yes & 24 & 14.8 \\
\hline Villositary infarcts & No & 138 & 85.2 \\
\hline & Yes & 42 & 25.9 \\
\hline Chorioamnionitis & No & 120 & 74.1 \\
\hline & Yes & 25 & 15.4 \\
\hline Meconium & No & 137 & 84.6 \\
\hline Yasculitis linfocitary, Thrombosis and/or Decidual necrosis & Yes & 10 & 6.2 \\
\hline Placenta disruption & No & 152 & 93.8 \\
\hline & Yes & 93 & 57.4 \\
\hline Nos & 6 & 42.6 \\
\hline No & 156 & 96.3 \\
\hline
\end{tabular}


Table 2

Univariate Analysis for Predictors of Risk of Chronic Hypertension in Women with Preeclampsia based on Placenta Histology at Manuel de Cèspedes Teaching Hospital

\begin{tabular}{|c|c|c|c|c|c|}
\hline Variable & Hypertension & $\begin{array}{l}\text { No } \\
\text { Hypertension }\end{array}$ & RR & $95 \% \mathrm{Cl}$ & $\begin{array}{l}p- \\
\text { value }\end{array}$ \\
\hline & $\mathbf{N} \%$ & $\mathbf{N} \%$ & & & \\
\hline Tenney parker changes & 523.8 & 1673.2 & 0.839 & $\begin{array}{l}0.374- \\
1.884\end{array}$ & 0.663 \\
\hline Placental hypermaturity & 233.3 & 466.7 & 1.209 & $\begin{array}{l}0.379- \\
3.857\end{array}$ & 0.757 \\
\hline Intervillositary thrombus & 1666.7 & 833.3 & 3.172 & $\begin{array}{l}2.064- \\
4.875\end{array}$ & $\dot{0.001}$ \\
\hline Villositary infarcts & 2559.5 & 1740.5 & 3.571 & $\begin{array}{l}2.229- \\
5.723\end{array}$ & $\dot{0} 001$ \\
\hline Chorioamnionitis & 1664.0 & 936.0 & 3.023 & $\begin{array}{l}1.953- \\
4.680\end{array}$ & $\begin{array}{l}<.001 \\
0.00\end{array}$ \\
\hline Meconium & 233.3 & 466.7 & 1.209 & $\begin{array}{l}0.379- \\
3.857\end{array}$ & 0.757 \\
\hline $\begin{array}{l}\text { Vasculitis linfocitary, } \\
\text { Thrombosis }\end{array}$ & 770.0 & 330.0 & 2.8 & $\begin{array}{l}1.715- \\
4.572\end{array}$ & 0.002 \\
\hline \multicolumn{6}{|l|}{ and/or Decidual necrosis } \\
\hline Endarteritis & 3941.9 & 5458.1 & 4.823 & $\begin{array}{l}2.165- \\
10.745\end{array}$ & $<.001$ \\
\hline
\end{tabular}

Table 3

Cox's Multivariate Model Analysis for Predictors of Risk of Chronic Hypertension in Women with Preeclampsia based on Placenta Histology at Manuel de Cèspedes

Teaching Hospital

\begin{tabular}{|lllll|}
\hline Variable & Hazard Ratio & \multicolumn{2}{l|}{ 95\% Confidence Interval } & p-value \\
\hline Chorioamnionitis & 1.697 & 1.443 & 3.416 & $0.038^{\star}$ \\
\hline Villositary infarcts & 1.657 & 1.264 & 2.848 & $0.048^{\star}$ \\
\hline Intervillositary thrombus & 1.529 & 1.231 & 3.197 & $0.02^{\star}$ \\
\hline Endarteritis & 1.242 & 1.115 & 1.804 & $0.025^{\star}$ \\
\hline${ }^{*}<0.05$ & & & & \\
\hline
\end{tabular}


The precise relationship between preeclampsia and later onset of hypertension remains an intriguing issue. The placenta has remained a point of emphasis among scholars with regard to both the aetiopathology of, and the later sequelae of, preeclampsia. Our study assessed the predictive histopathologic lesions of the placenta for chronic hypertension in women with preeclampsia admitted at Carlos Manuel de Cèspedes Teaching Hospital at twelve weeks postpartum. Results indicated that placental abnormalities, that is; chorioamnionitis ( $\mathrm{HR}=1.697,95 \% \mathrm{Cl}: 1.443-3.416, p=0.038)$, villositary infarcts $(\mathrm{HR}=1.657,95 \% \mathrm{Cl}: 1.264-2.848, p=0.048)$, intervillositary thrombus $(\mathrm{HR}=1.529,95 \% \mathrm{Cl}: 1.231-$ $3.197, p=0.020)$, and endarteritis ( $\mathrm{HR}=1.242,95 \% \mathrm{Cl}: 1.115-1.804, p=0.025)$ were independently associated with high risk for developing chronic hypertension at twelve weeks. Despite paucity of information regarding relatively similar studies conducted previously, we noted supportive findings by Krielessi et al. (25) at Alexandra Maternity University Hospital in Greece who in their study to investigate the extent of placental histological lesions associated with blood pressure levels in pregnancies complicated by hypertension, histological abnormalities such as the presence of villous fibrinoid necrosis, villous hypermaturity and placental infarction were observed significantly more often in the hypertensive placentas. Their study noted that the extensive placental lesions were significantly associated with higher levels of hypertension. Similarly also, in Venezuela, Castejón and Pérez's (6) placental histopathology studies revealed severe degenerative changes to the placental villi with disorganized placenta structure provoked by chronic hypertension. In their study, the placenta showed a significant number of syncytial knots, fibrinoid necrosis, calcification and hyalinization. Meanwhile, Obiri et al. (26) in Ghana revealed syncytial knots as the main contributor to placental pathology in women diagnosed with preeclampsia; this was about ten-fold more frequent in preeclampsia than non-preeclampsia placentas. For our case however, endarteritis $93(57.4 \%)$ was the most common pathological lesion noted.

Based on these findings therefore, and as it has been suggested by Garovic and August (27), it is possible that the preeclampsia induced long-term irreversible vascular changes arising from these placental lesions may be responsible for the overall increased risk for chronic hypertension and other related longterm cardiovascular sequel of preeclampsia.

\section{Conclusion}

A remarkable number of patients with preeclampsia are candidates for future chronic hypertension and its related cardiovascular complications. Recognition of these predictors therefore may be of value towards early diagnosis for early interventions.

\section{Abbreviations}

$\mathrm{H} \& \mathrm{E}$

Haematoxylin and Eosin, mmHg:Millimeters of Mercury

\section{Declarations}




\section{Ethics approval and consent to participate in the study}

Voluntary enrollment of all the study participants was done. Informed written consent from participants was obtained after fully explaining the details of the study in Spanish, the national language for Cuba. An informed consent document in Spanish language approved by the research ethics committee of Carlos Manuel de Cèspedes Teaching Hospital was signed by every participant, the investigator and a witness. Participants were not forced to enroll for the study if they did not want to. A participant was free to withdraw from the study at any time she wished, without coercion or compromise of care that she was entitled to. The study was approved by the Research Ethics Committee of Carlos Manuel de Cèspedes Teaching Hospital, approval number; 11 of 2016.

\section{Consent for publication}

Not applicable.

\section{Availability of data and materials}

The datasets used and/or analyzed during the current study are available from the corresponding author on reasonable request.

\section{Competing interests}

We bear no any competing interests to declare.

\section{Funding}

No funding was obtained for this study.

\section{Authors' contributions}

SB was involved in conceptualization and design of the study, analysis, manuscript writing, and coordination of the study team. YF participated in conceptualization, design, data collection, and analysis of the study. DN and AA made substantial contribution during data collection and analysis. YC contributed towards study design, data and sample collection, and analysis of samples in the histopathology laboratory. RS made substantial contribution towards study design, literature search and general revision of the manuscript. All the authors had sufficient time to read and approve the final manuscript.

\section{Acknowledgements}

The authors appreciate all the participants for having consented to participate in the study.

\section{References}


1. Sibiude J, Guibourdenche J, Dionne M, Ray C Le, Tsatsaris V. Placental Growth Factor for the Prediction of Adverse Outcomes in Patients with Suspected Preeclampsia or Intrauterine Growth Restriction. PLoS One. 2012;7(11):1-8.

2. Subki AH, Algethami MR, Baabdullah WM, Alnefaie MN, Alzanbagi MA, Alsolami RM, et al. Prevalence, Risk Factors, and Fetal and Maternal Outcomes of Hypertensive Disorders of Pregnancy: A Retrospective Study in Western Saudi Arabia. Oman Med Journal. 2018;33(5):409-15.

3. Sa L, Bowyer L, Lust K, Lp M, Morton M, Ra N, et al. Guideline for the Management of Hypertensive Disorders of Pregnancy. Soc Obstet Med Aust New Zeal. 2014;

4. Portelli M, Baron B. Clinical Presentation of Preeclampsia and the Diagnostic Value of Proteins and their Methylation Products as Biomarkers in Pregnant Women with Preeclampsia and their Newborns. J Pregnancy. 2018;2018(5):1-23.

5. Amougou SN, Mbita SMM, Danwe D, Tebeu P-M. Factor associated with progression to chronic arterial hypertension in women with preeclampsia in Yaoundé, Cameroon. Pan African Med. 2019;200(33):1-7.

6. Castejón OC, Pérez MA. The Placental Villi During Chronic Hypertension. J Emerg Rare Dis. 2018;1(2):1-5.

7. Delfín M, Caballero P, Luis IJ, Álvarez L, Dueñas IA, De R, et al. Guía cubana de diagnóstico, evaluación y tratamiento de la hipertensión arterial. Cuban guide for hypertension diagnosis, evaluation and treatment. Rev Cubana Med. 2017;56(4):242-321.

8. Lardoeyt R, Vargas G, Lumpuy J, García R, Torres Y. Contribution of Genome - Environment Interaction to Pre-eclampsia in a Havana Maternity Hospital. MEDICC Rev. 2013;15(3):143-78.

9. Ndayambagye EB, Nakalembe M, Kaye DK. Factors associated with persistent hypertension after puerperium among women with pre- eclampsia / eclampsia in Mulago hospital , Uganda. BMC Pregnancy Childbirth. 2010;10(12):1-7.

10. Fathy HM, Makled AK, Sabaa HA, Yonis MA. Incidence and Risk Factors That Predict Chronic Hypertension after Delivery in Women with Hypertensive Disorders of Pregnancy. Egypt J Hosp Med. 2017;69(October):1901-7.

11. Fox R, Kitt J, Leeson P, Aye CYL, Lewandowski AJ. Preeclampsia: Risk Factors, Diagnosis , Management, and the Cardiovascular Impact on the Off spring. J Clin Med. 2019;1625(8):1-22.

12. Cunningham FG, Leveno KJ, Bloom SL, Dashe JS, Hoffman BL, Casey BM. Williams Obstetrics. 25th ed. McGraw-Hill Education; 2018.

13. Ferdinand KC, Fleg JL. Hypertension Across a Woman 's Life Cycle. J Am Coll Cardiol. 2019;71(16):1797-813.

14. Institute of Obstetricians and Gynaecologists, Royal College of Physicians of Ireland and the Clinical Strategy and Programmes Division HSE. Clinical Practice Guideline: The Management Of Hypertension In Pregnancy. 2019;(2016):1-32.

15. Saini V, Gupta M, Kumar DS, Singh H, Gupta SK. Preeclampsia: Postpartum Resolution of Hypertension, Proteinuria and Serum N-terminal B-type Natriuretic Peptide. Indian J Med Biochem. 
2019;23(2):278-86.

16. Nakimuli A, Elliott AM, Kaleebu P, Moffett A, Mirembe F. Hypertension Persisting after Pre-Eclampsia: A Prospective Cohort Study at Mulago Hospital , Uganda. PLoS One. 2013;8(12):1-7.

17. Costa ML, Cecatti JG. Preeclampsia in 2018: Revisiting Concepts, Physiopathology, and Prediction. Sci World J. 2018;2018(3):1-9.

18. Ezeigwe CO, Okafor Cl, Eleje GU, Udigwe GO, Anyiam DC. Placental Peripartum Pathologies in Women with Preeclampsia and Eclampsia. Obstet Gynecol Int. 2018;2018(2):1-8.

19. Eze ED, Barasa A, Adams MD, Rabiu KM, Sulaiman SO, Ponsiano N. Determination, knowledge and prevalence of pregnancy-induced hypertension/eclampsia among women of childbearing age at Same District Hospital in Tanzania. Int J Med Med Sci. 2018;10(2):19-26.

20. Strobino D, Werner E, Mandal M. Literature Review: Antihypertensive Medication in Pregnancy An Update from the 2011 WHO Recommendations for Prevention and Treatment of Pre-eclampsia and Eclampsia. Jhpiego [Internet]. 2015; Available from: www.jhpiego.org/accelovate.

21. Shopen N, Schiff E, Koren-morag N, Grossman E. Factors That Predict the Development of Hypertension in Women With Pregnancy-Induced Hypertension. Am J Hypertens. 2016;29(1):141-6.

22. Hossain S, Roy S, Kirk K, Warren C. Hypertensive Disorders in Pregnancy: Assessing Postnatal Quality of Care and Outcomes for Women and Their Infants in Bangladesh. Popul Counc Inc. 2019;1-26.

23. Jhee JH, Lee S, Park Y, Lee SE, Kim YA, Kang W, et al. Prediction model development of late-onset preeclampsia using machine learning-based methods. PLoS One. 2019;14(8):1-12.

24. Daniel WW. Biostatistics. A Foundation for Analysis in the Health Sciences. John Wiley \& Sons, Inc.; 2009.

25. Krielessi V, Papantoniou N, Papageorgiou I, Chatzipapas I, Manios E, Zakopoulos N, et al. Placental Pathology and Blood Pressure's Level in Women with Hypertensive Disorders in Pregnancy. Obstet Gynecol Int. 2012;2012(1):1-6.

26. Obiri D, Erskine IJ, Oduro D, K KA, Jones A, Gyan BA, et al. Histopathological lesions and exposure to Plasmodium falciparum infections in the placenta increases the risk of preeclampsia among pregnant women. Sci Rep. 2020;10(8280):1-10.

27. Garovic VD, August P. Preeclampsia and the Future Risk of Hypertension: The Pregnant Evidence. Curr Hypertens Rep. 2014;15(2):1-14. 